\title{
Dynamic Resolution
}

\section{Desymmetrization of 2-Cyano- $\mathrm{N}$-tosylbenzylidenimine with Thiols and Organocatalytic Heterocyclization by Dynamic Resolution: Mechanism Investigation}

\author{
Amalia Velardo, ${ }^{\text {a] }}$ Vito Capaccio, ${ }^{[a]}$ Tonino Caruso, ${ }^{[a]}$ Antonia Di Mola, ${ }^{[a]}$ Antonio Massa, ${ }^{[a]}$ \\ Consiglia Tedesco, ${ }^{[a]}$ Lucia Caporaso, ${ }^{[a]}$ Laura Falivene, ${ }^{*[b]}$ and Laura Palombi*[a]
}

Abstract: Integrated experimental and computational approach provides a rationale for the mode of action of cinchonabased alkaloids as chiral receptors in the observed dynamic chiral resolution of the titled tandem reaction. In particular, a mechanism based on a dynamic kinetic asymmetric transformation has been unravelled in detail. Furthermore, the crucial role of "distal" $\mathrm{H}$-bonding donor functionality in directing the enantioselectivity reversal of homochiral cinchona-based catalysts has been convincingly explained. The access to enantiopure tertiary isoindolinone $N, S$-acetals has been achieved for the first time.

\section{Introduction}

Given the almost ubiquitous presence of heterocyclic compounds in bioactive molecules, their synthesis, especially in enantio-enriched form, represents a major challenge in organic chemistry. To this purpose, since about two decades, organocatalysis (including the phase transfer organocatalysis) ${ }^{[1]}$ has been bursting on to the literature scene as a privileged methodology thanks to its fascinating features of selectivity, practicality and low toxicity. As well known, an organocatalyst is particularly effective in facilitating highly stereo-controlled bond-forming processes and this is very impressive especially when only non-covalent interactions (usually multiple $\mathrm{H}$-bonding interactions) between the catalyst and the substrates are involved. The versatility of the organocatalysts is further attested by their successful use in remarkable protocols of dynamic kinetic resolution (DKR), dynamic kinetic transformations (DYKAT) and dynamic thermodynamic resolution (DTR) which, though less frequently found in the literature, are emerging as additional valuable resources for the asymmetric synthesis of heterocycles with multiple chiral centers. ${ }^{[2,3]}$

As a consequence, if at first research efforts were principally focused on the synthetic targets, nowadays many studies aim to understand how to improve organocatalysts function. ${ }^{[4]}$ On the other hand, getting mechanistic information is crucial

[a] Dipartimento di Chimica e Biologia, Università degli Studi di Salerno Via Giovanni Paolo II, 132, 84084, Fiscyano (SA), Italy

E-mail:Ipalombi@unisa.it http://docenti.unisa.it/laura.palombi

[b] King Abdullah University of Science and Technology, Chemical and Life Sciences and Engineering, Kaust Catalysis Center Thuwal 23955-6900, Saudi Arabia E-mail: laura.falivene@kaust.edu.so

Supporting information and $O R C I D(s)$ from the author(s) for this article are available on the WWW under https://doi.org/10.1002/ejoc.201901499. to design a successful synthetic strategy by limiting the timewasting screening experiments.

Recently, we have reported the successful use of the organocatalysts cupreidine and cupreine in the asymmetric cascade addition of thiols to the 2-cyano- $\mathrm{N}$-tosylbenzylidenimine followed by intramolecular closure on the $\mathrm{CN}$ group. ${ }^{[5]}$ This reaction disclosed the first access to a new class of enantioenriched $N, S$-acetals ${ }^{[6]}$ with a cyclic structure closely related to the isoindolinonic core, a relevant architecture in the panorama of the pharmacologically active heterocycles (Scheme 1). ${ }^{[7]}$

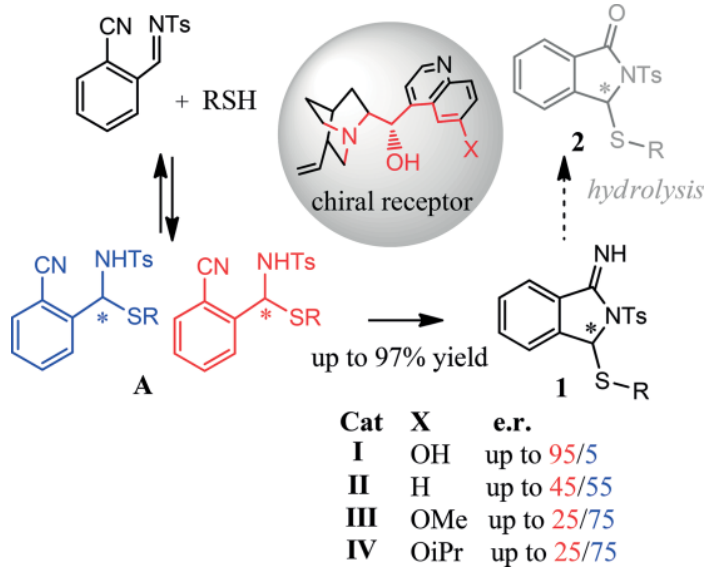

Scheme 1. Synthesis of $\mathbf{1}$ and possible strategy for a straightforward access to chiral $N, S$-acetals with an isoindolinonic core $\mathbf{2}$

During the set-up of the reaction, we found that the single chiral center of compound $\mathbf{1}$ is formed downstream an organocatalytic dynamic resolution process with the organocatalyst ${ }^{[8]}$ acting as a chiral receptor for the pre-formed racemic intermediate $\mathbf{A}$.

As already reported in our previous work, ${ }^{[5]}$ the nature of the group $X$ on the catalyst has a meaningful effect on the 
Table 1. Control experiments examining the dynamic characteristics of the title reaction using various catalysts and reaction conditions.

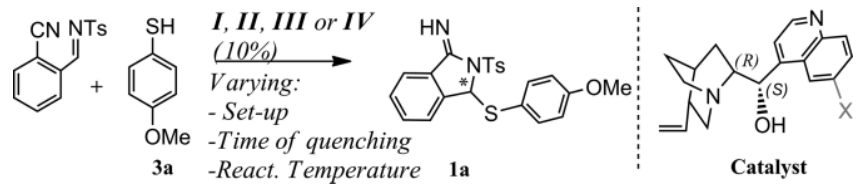

\begin{tabular}{|c|c|c|c|c|c|c|c|c|c|c|c|}
\hline Entry & Cat. & $x$ & $T\left[{ }^{\circ} \mathrm{C}\right]$ & Yield [\%] & e.r. & Entry & Cat. & $X$ & $\left.\pi^{\circ} \mathrm{C}\right]$ & Yield [\%] & e.r. \\
\hline $1^{[\mathrm{a}]}$ & I & $-\mathrm{OH}$ & r.t. & 83 & $76: 24$ & $8^{[a]}$ & II & $-\mathrm{H}$ & -40 & trace & nd \\
\hline $2^{[\mathrm{a}]}$ & II & $-\mathrm{H}$ & r.t. & 90 & $46: 54$ & $9^{[c]}$ & II & $-\mathrm{H}$ & 0 & 32 & $45: 55$ \\
\hline $\mathbf{3}^{[\mathrm{a}]}$ & III & -OMe & r.t. & 86 & $38: 62$ & $10^{[\mathrm{a}]}$ & III & -OMe & -20 & 83 & $25: 75$ \\
\hline $\mathbf{4}^{[\mathrm{a}][5]}$ & I & $-\mathrm{OH}$ & -40 & 80 & $91: 9$ & $11^{[c, d]}$ & III & -OMe & -20 & 28 & $27: 73$ \\
\hline $5^{[\mathrm{b}]}$ & I & $-\mathrm{OH}$ & -40 & 79 & $90: 10$ & $12^{[a]}$ & III & -OMe & -40 & 15 & $25: 75$ \\
\hline $6^{[c, d]}$ & I & $-\mathrm{OH}$ & -40 & 49 & $90: 10$ & $13^{[b]}$ & IV & -OMe & -20 & 92 & $27: 73$ \\
\hline $7^{[\mathrm{a}]}$ & II & $-\mathrm{H}$ & -20 & 60 & $45: 55$ & $14^{[\mathrm{b}]}$ & IV & $-\mathrm{OiPr}$ & -20 & 90 & $25: 75$ \\
\hline
\end{tabular}

[a] A mixture of 2-cyano- $N$-tosylbenzylidenimine (1 equiv.) and catalyst (10\%), was stirred in DCM (56 mM) for 10 min at the temperature indicated. Then 3a (2 equiv.) was added and the reaction was prolonged until complete conversion of the starting material. [b] A mixture of 2-cyano- $N$-tosylbenzylidenimine (1 equiv.) and 3a (2 equiv.) was stirred in DCM $(56 \mathrm{~mm}$ ) at r.t. for $10 \mathrm{~min}$ until the formation of the intermediate $\mathbf{A}$ was complete (NMR analysis). The temperature has been then set as indicated in table the catalyst (10\%) was added and the reaction was prolonged until complete conversion of the starting material. [c] The reaction was performed using the protocol indicated in b). The reaction was stopped when NMR analysis indicated ca $50 \%$ conversion of the intermediate $\mathbf{A}$. [d] 1 equiv. of $\mathbf{3 a}$ was used.

enantiomeric degree as well as on the identity of the major enantiomer obtained. In details, the presence of the two $\mathrm{H}$ bonding donors on the catalyst molecule, as in cupreidine (I), is an important pre-requisite to maximize the degree of stereoselectivity of the process. The use of parent catalysts like cinchonine (II) or quinidine (III) leads to a significant drop of the enantiomeric ratio, as well as to an enantioselectivity reversal, despite of the same chirality of the catalyst scaffold. The almost unique characteristics of this stereochemical pathway in the context of such a metal-free catalysis spurred us to undertake a mechanistic study to elucidate how the molecular recognition occurs and the role of the catalyst through the two steps of the reaction. To have a reliable mechanistic insight, both experimental and theoretical investigations have been integrated in this study.

\section{Results and Discussion}

\section{Experimental Data}

As already mentioned, the presence of an additional $\mathrm{H}$-bonding donor at the $\mathrm{C}^{6}$ position, besides affecting the stereoselectivity level of the process, also determinates the enantiodirection.

To exclude that the stereochemical outcome observed in the presence of II, III, IV could be due to a different mode of action of these catalysts, we carried out some control experiments using the thiol $\mathbf{3 a}$ as a reference nucleophile in the model reaction reported in Table 1. By these data we established the following:

- Since the enantioselectivity of the reaction is not affected by the presence of intermediate $\mathbf{A}$ as a racemic mixture at the beginning of the catalytic cycle (entries 5, 9, 11, 13, 14), an irreversible asymmetric addition ${ }^{[6]}$ of the thiol to the imine should not be expected for any of the catalysts.

- On the other hand, when the reaction is stopped at ca. $50 \%$ of the conversion (compare entries 5 and 6, 7 and 9, 10 and $11)$, the e.r. remains constant, regardless of the grade of progress. This clearly excludes the occurrence of a mixed mechanism partially based on a classical (not dynamic) resolution, for all the catalysts examined.

- The comparison of the results obtained in presence of 2 equiv. of thiol (as in the optimized procedure indicated in ref. 5) with those obtained with 1 equiv. of thiol (entries 6 and 11) indicates that no relevant change occurs in the enantioselectivity, allowing us to exclude that two molecules of thiol are involved in the catalytic cycle.

\section{Determination of the Absolute Configuration of the Major Enantiomer}

Since any attempt to directly achieve the homochiral crystallization of the product $\mathbf{1} \mathbf{a}$ failed, ${ }^{[9]}$ in order to determine the absolute configuration of the major enantiomer obtained with catalyst I, we focused our attention on the isoindolinonic derivative $\mathbf{2 a}$, affordable through the hydrolysis of the imine functionality.

Standard hydrolysis conditions established by us for similar cyclic imino-amides ${ }^{[10]}$ have proved to be scarcely effective in this case leading to the expected product $\mathbf{2 a}$ in modest yield with an unpleasant loss in ee.

At least, a significant improvement of the chemical yield has been obtained by a short-time microwave-assisted reaction, under the conditions reported in Scheme 2 (for optimization of the hydrolysis reaction see ESI).

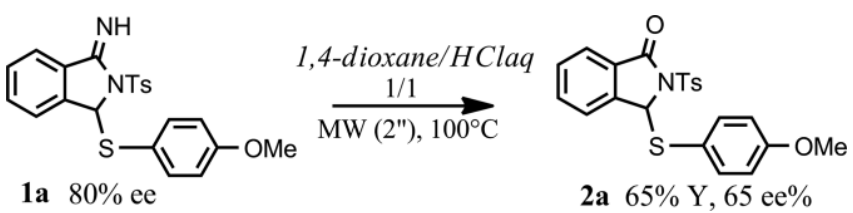

Scheme 2. Microwave-assisted hydrolysis of $\mathbf{1 a}$

In contrast with $\mathbf{1}$, the derivatives $\mathbf{2}$ demonstrated to be chemically and configurationally stable compounds, indefinitely storable at r.t., and likewise compatible with the acid conditions 
of the hydrolysis. Remarkably, to the best of our knowledge, this represents the first access to new enantioenriched isoindolinones having a potentially reactive $N, S$-acetal functionality.

Pleasantly, a sequential process of hetero- and homo-crystallization yielded colorless needle-like single crystals of enantiopure $\mathbf{2 a}$ suitable for X-ray diffraction analysis which definitively revealed the absolute configuration $(\boldsymbol{R})$ of the major enantiomer (Figure 1).

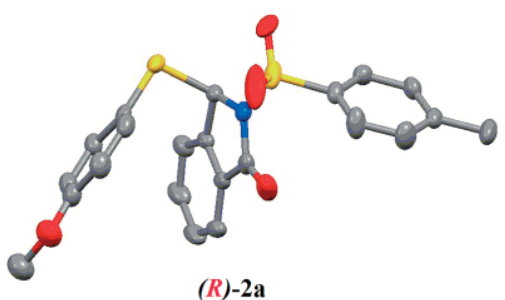

Figure 1. X-ray structure of the major enantiomer obtained with catalyst $\mathbf{I}$.

\section{Computational Studies}

Since the interconversion of the stereolabile enantiomers $\mathbf{A}(\boldsymbol{R})$ $\leftrightharpoons \mathbf{A}(\mathbf{S})$ is expected to occur through a dynamic equilibration with the starting materials (imine and thiol), we opened our investigations by analyzing the energy scenarios for the addition of the representative thiol $\mathbf{3 a}$ to the imine, both under catalyst-free conditions and in presence of the best performing catalyst I.

\section{Energy Scenario for the Uncatalyzed Addition}

As indicated in Scheme 3, under catalyst-free conditions, the lowest-energy reaction pathway involves a six-membered transition state $\mathbf{S}$ - $\boldsymbol{A}^{\prime}$ lying $24.5 \mathrm{kcal} / \mathrm{mol}$ higher in energy than the reactants $\boldsymbol{S}$ and $27.8 \mathrm{kcal} / \mathrm{mol}$ higher than the final adduct $\mathbf{A}$. Indeed, it is worth to note that the alternative direct formation of $\mathbf{A}$ is unfavored due to a strained four-membered ring transition state.

\section{Energy Scenario for the Catalyzed Process}

In the presence of $\mathbf{I}$, a proton transfer from the initial racemic mixture of $\mathbf{A}$ to the catalyst leads to the formation of two diastereomeric ion-pairs $\mathbf{A}-\mathbf{I}(\boldsymbol{R})$ and $\mathbf{A}-\mathbf{I}(\mathbf{S})$. Based on the feasible interactions between the two moieties, different ion-pairs have been located. ${ }^{[11]}$

Since a dynamic equilibrium among the different species is expected, we discuss here only the results obtained for the thermodynamic ion-pairs A-I (see Figure 2) and the lowest energy profiles for the reactions considered.
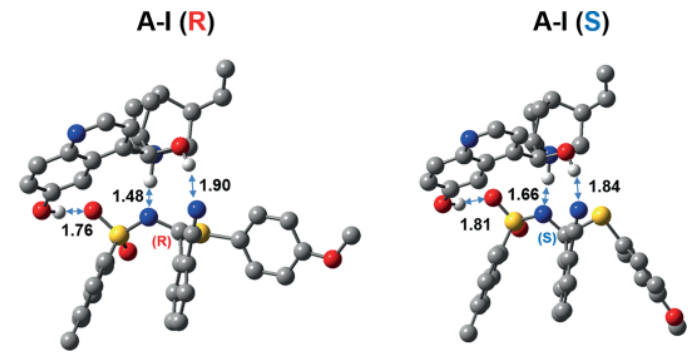

Figure 2. Optimized geometries of A-I (R) and A-I (S).

Calculations reveal that both the thermodynamic ion-pairs $\mathbf{A}-\mathbf{I}(\boldsymbol{R})$ and $\mathbf{A}-\mathbf{I}(\mathbf{S})$ are strongly associated and stabilized by a similar pattern of three hydrogen bonds. Yet, the $\mathbf{A}-\mathbf{I}(\boldsymbol{R})$ complex is $1.3 \mathrm{kcal} / \mathrm{mol}$ more stable of the corresponding $\mathbf{A}-\mathbf{I}(\mathbf{S})$ due to the formation of a tighter ion-pair (Figure 2).

Starting from the binary complexes $\mathbf{A}-\mathbf{I}(\boldsymbol{R})$ and $\mathbf{A}-\mathbf{I}(\mathbf{S})$, we proceeded to the determination of the energy barriers for both the $\mathbf{A}(\boldsymbol{R}) \rightleftarrows \mathbf{A}(\boldsymbol{S})$ interconverting equilibrium and the following irreversible heterocyclization under catalyzed conditions. The energy profile depicted in Scheme 4 rationalizes the role of the catalyst I in the whole process leading to the final product $\mathbf{1}$, with the blue and the red lines referred to the $\boldsymbol{S}$ and $\boldsymbol{R}$ enantiomer, respectively. As it emerges by the graph, the highest energy barrier involved in the equilibrium $\mathbf{A}-\mathbf{I}(\boldsymbol{R}) \rightleftarrows \mathbf{A}-\mathbf{I}(\mathbf{S})$ via the retro-addition reaction is $14.3 \mathrm{kcal} / \mathrm{mol}$, that is nearly two times lower that the one required by the uncatalyzed process $(27.8 \mathrm{kcal} / \mathrm{mol}$, Scheme 3$)$. This clearly claims for an asymmetrical $\mathbf{A}(\boldsymbol{R}) \leftrightharpoons \mathbf{A}(\mathbf{S})$ interconversion induced by the catalyst, rather than a spontaneous racemization. ${ }^{[12]}$ Consequently, in the presence of the catalyst I, a $\Delta G^{\circ}$ of $1.3 \mathrm{kcal} / \mathrm{mol}$ will definitively shift the above-mentioned equilibrium in favor of the $\mathbf{A}(\boldsymbol{R})$ enantiomer.

Notably, based on the more stable $\mathbf{B}-\mathbf{A}(\boldsymbol{R})$ and $\mathbf{B}-\mathbf{A}(\mathbf{S})$ TSs located (see Figure 3), a $\Delta G^{\neq}$of $1.0 \mathrm{kcal} / \mathrm{mol}$ also indicates that $\mathbf{B} \rightarrow \mathbf{A}(\boldsymbol{R})$ process is kinetically favored over $\mathbf{B} \rightarrow \mathbf{A}(\mathbf{S})$. Indeed, a glance to the Figure 3 shows the important role played by the $\mathrm{C}^{6^{\prime}}-\mathrm{OH}$ in favoring the $\mathbf{B}-\mathbf{A}(\boldsymbol{R})$ TS by means of stabilizing interactions with the sulfur atom and especially with the ipsocarbon of the aryl sulfide moiety. On the side of the kinetically controlled heterocyclization, calculations reveal that the energy barriers expected for the ring closure are 18.5 and $20.2 \mathrm{kcal} /$ mol for $\boldsymbol{R}$ and $\boldsymbol{S}$ enantiomer, respectively. The lowest barrier for the kinetically controlled process is therefore more than $4 \mathrm{kcal} /$ mol higher than that for the $\mathbf{A}(\boldsymbol{R}) \leftrightharpoons \mathbf{A}(\mathbf{S})$ interconversion.

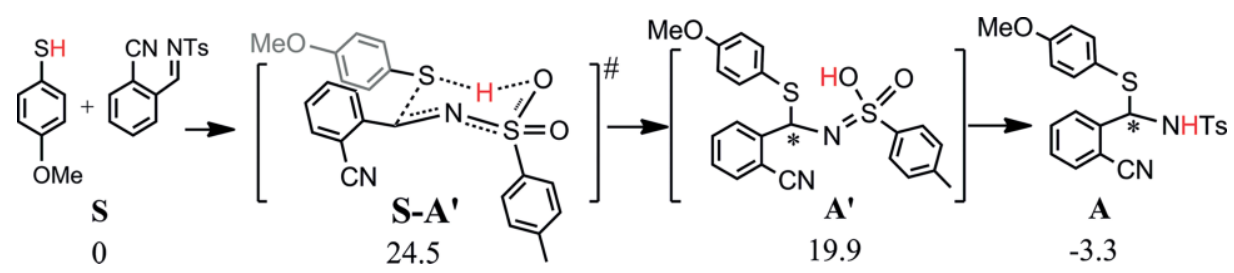

Scheme 3. Reaction pathway and free-energy values $\left(\mathrm{kcal} / \mathrm{mol}\right.$ in $\mathrm{CHCl}_{3}$ ) for the uncatalyzed process. 


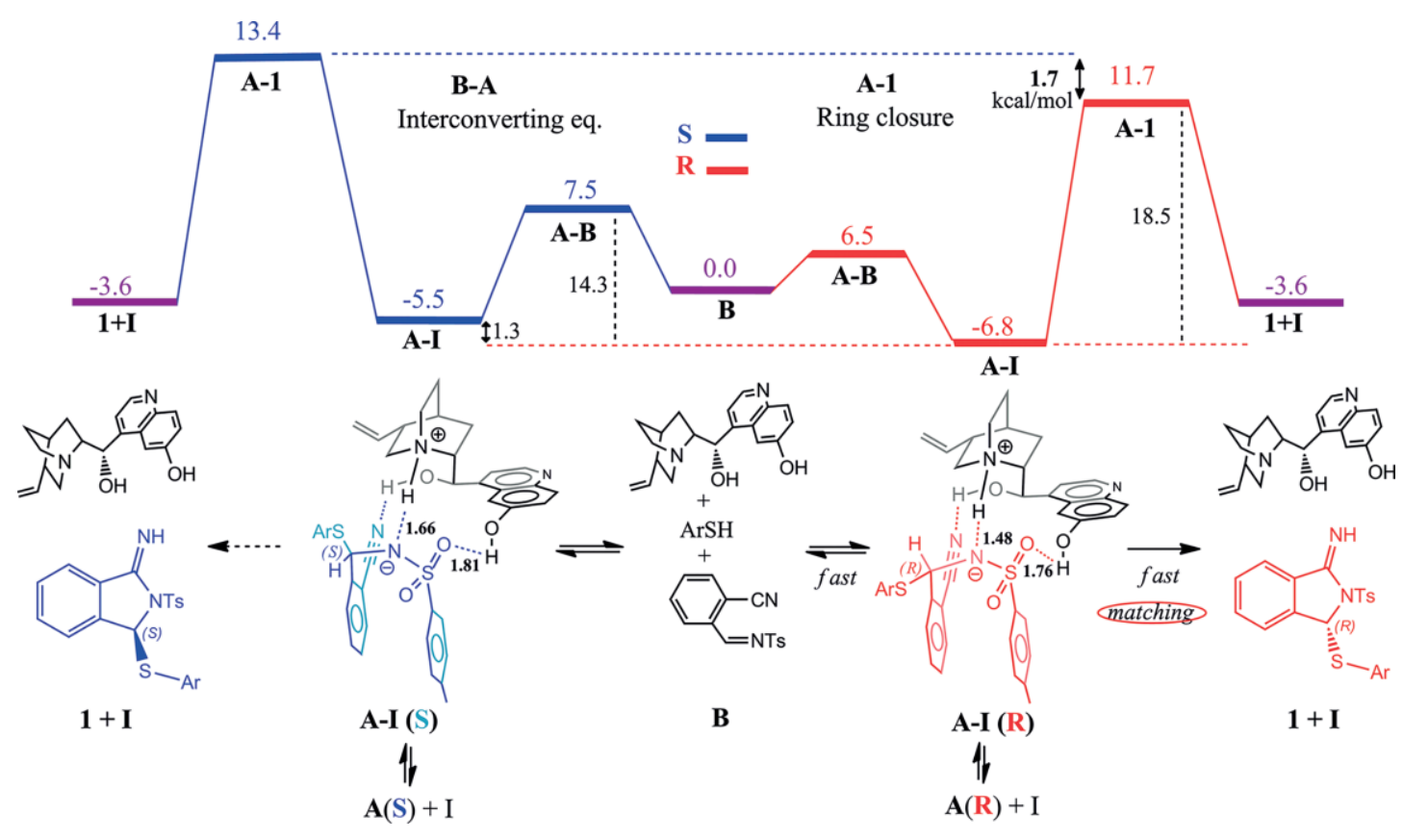

Scheme 4. Free energy $\left(\mathrm{kcal} / \mathrm{mol}\right.$ in $\mathrm{CHCl}_{3}$ ) profile for the process catalyzed by $\mathbf{I}$.

$\mathrm{B}-\mathrm{A}(R)$

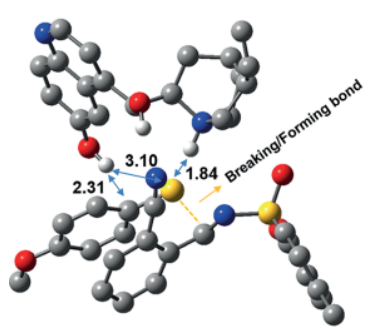

Figure 3. Optimized geometries of $\mathbf{B}-\mathbf{A}(\boldsymbol{R} / \mathbf{S})$ TSs.

Given the above, the overall reaction barrier (see Scheme 4) calculated with respect to the absolute energy minimum along the reaction profile is predicted to be $1.7 \mathrm{kcal} / \mathrm{mol}$ Lower for the $\boldsymbol{R}$ enantiomer with respect to $\boldsymbol{S}$, leading to an enrichment in $\mathbf{1 - ( R )}$, in good agreement with the experimental results.

The different stability of the diastereoisomeric A-1 TSs and, as a consequence, the easier accessibility for the $\boldsymbol{R}$ configuration of the product $\mathbf{1}$, can be related to the different pattern of hydrogen bonds established by the two enantiomers with the catalyst in this crucial event (Figure 4).

In fact, during the ring-closure, the increasing Lewis basicity of the nitrogen atom of the cyano group is assisted by the strong phenol-like acidic function at the $C^{6^{\prime}}$ in the most favored A-1 $(\boldsymbol{R})$ TS, and by the weaker acidic hydroxyl at the $C^{9}$ in the most stable $\mathbf{A - 1}(\mathbf{S})$. To sum up, theoretical data reveal that the $-\mathrm{OH}$ on the quinoline moiety of the catalyst $\mathbf{I}$ is involved both in the enantiomeric recognition of $\mathbf{A}$ [making the $\mathbf{A}-\mathbf{I}(\boldsymbol{R})$ complex thermodynamically and kinetically favored over $\mathbf{A}-\mathbf{I}(\mathbf{S})]$ and in the stereo-differentiation of the key $\mathbf{A}-\mathbf{1}(\boldsymbol{R} / \mathbf{S}) \mathrm{TS}$, pleasantly producing a matching ${ }^{[13]}$ between the kinetically favored ringclosure and the enantiomeric equilibrium.
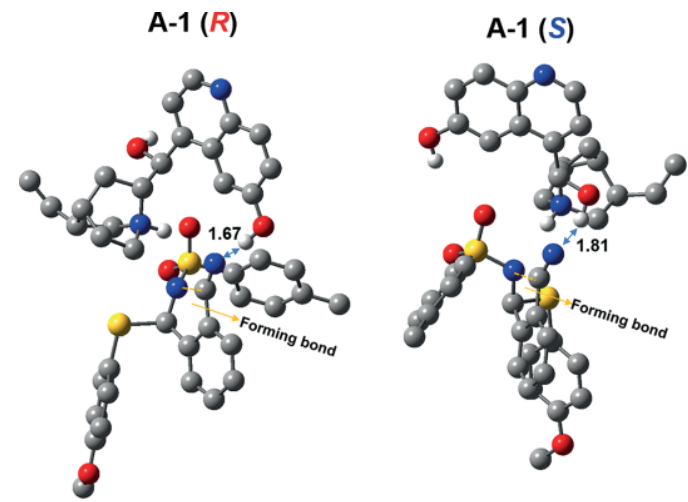

Figure 4. Optimized geometries of $\mathbf{A - 1}(\boldsymbol{R} / \mathbf{S})$ with cat. I.

\section{Enantioselectivity Reversal with Catalyst III}

As already mentioned, the use of the catalysts where the hydroxyl at the $\mathrm{C}^{6^{\prime}}$ is replaced with an -OR functionality (quinidine III and its derivative IV) entails the preferential cyclization of the S-enantiomer. On the other hand, the control experiments of Table 1 let us infer that these catalysts act with the same mechanism observed for $\mathbf{I}$.

Consequently, in order to rationalize this interesting enantioselectivity reversal despite the homochirality of the catalyst scaffold, we focused on the relative energies of the TSs [A-1III(R)/A-1-III(S)] involved in the rate-determining step whereby III is used as catalyst.

As shown in Figure 5, in both the stereoisomeric TSs, the cyclization is assisted by a hydrogen bond between the hydroxyl at the $C^{9}$ of the catalyst and the cyano group of the two enantiomeric adducts A. However, in A-1-III $(\boldsymbol{R})$, in order to enable this interaction, the quinoline moiety ends up at short distances from the substrate with a consequent enhance of the 
energy of the $\boldsymbol{R}$ ring closure TS. Therefore, based on calculations, a preferential cyclization of the $\boldsymbol{S}$ enantiomer is expected, nicely confirming the experimental results.
A-1-III $(R)$

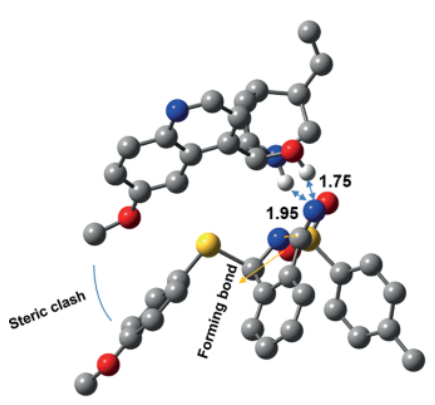

$0.0 \mathrm{kca} / \mathrm{mol}$

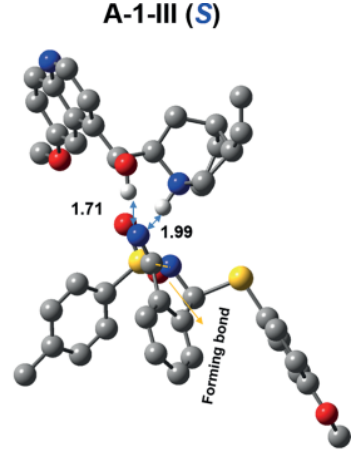

$-1.6 \mathrm{kcal} / \mathrm{mol}$
Figure 5. Optimized geometries of $\mathbf{A}-\mathbf{1}-\mathbf{I I I}(\boldsymbol{R} / \mathbf{S})$ with cat. III with relative free energies in $\mathrm{CHCl}_{3}$.

\section{Conclusions}

In summary, experimental observations and computational studies provide a rationale for the mechanism of the title dynamic resolution with cupreidine as organocatalyst. The comparative analysis with the molecular parent quinidine evidences that the $\mathrm{OH}$ functionality in $\mathrm{C}^{6^{\prime}}$ on the cupreidine molecule plays a key role both in the enantioconverting equilibrium and in the following cyclization step, directing and enforcing the stereoselectivity of this cinchona-derived catalyst. Indeed, depending on the presence of different substituents on the quinoline moiety, a starling enantioselectivity reversal can be produced with homochiral cinchona catalysts, such as III and IV.

Furthermore, we have reported the first access to enantioenriched tertiary isoindolinones $N, S$-acetals, as well as the possibility to achieve these important heterocycles in enantiopure form by crystallization.

\section{Experimental Section}

For detailed experimental information, typical procedures, spectra and chromatograms of all the new compounds and relevant coordinates see the ESI. Catalyst II and III are commercially available, starting tosyl-imine, ${ }^{[5]}$ cupreidine ${ }^{[14 a]}$ and catalyst $\mathbf{I V}^{[14 b]}$ have been prepared as reported in the literature.

X-ray Crystallography: CCDC 1941732 contains the supplementary crystallographic data for compound (R)-2a. These data can be obtained free of charge from The Cambridge Crystallographic Data Centre.

Computational Details: All the DFT geometry optimizations were performed at the GGA PBE0-D3 ${ }^{[15,16]}$ level with the Gaussian09 package. ${ }^{[17]}$ The electronic configuration of the systems was described with the SVP basis set for $\mathrm{H}, \mathrm{C}, \mathrm{N}, \mathrm{O} .{ }^{[18]}$ Geometries were characterized as minimum or transition state through frequency calculations: all transition states exhibit only one large imaginary frequency corresponding to the stretching coordinate of the forming bond, while the minimum energy structures have only positive eigenvalues of the Hessian matrix.
Moreover, intrinsic reaction coordinate (IRC) calculations were performed to verify the connectivity of all TSs with their corresponding minima.

Single point energy calculations on the PBE0-D3/SVP geometries using the M06-2X ${ }^{[19]}$ functional and the triple- $\zeta$ TZVP ${ }^{[20]}$ basis set on main group atoms were performed in order to obtain more accurate energy values. To this extent, different functionals have been tested for the single point energy calculations to check the reproducibility of the reported results. The final protocol has been chosen in agreement with the results reported in references, ${ }^{[11 b][5]}$ and. ${ }^{[21]}$

Solvent effects were included performing single point calculations on the optimized geometries with the PCM model using $\mathrm{CHCl}_{3}$ as solvent. ${ }^{[22,23]}$ With the assumption that there is no difference in the zero point correction and thermal contributions between solution and gas phase, the free energies are obtained as $G_{\text {solution }}=$ $G_{\text {gas }}(\mathrm{PBE} 0-\mathrm{D} 3 / \mathrm{SVP})+\left[G_{\text {solvent,PCM }}(\mathrm{M} 06-2 \mathrm{X} / \mathrm{TZVP})-E_{\text {gas }}(\mathrm{PBE} 0-\mathrm{D} 3 /\right.$ SVP)] (see ESI for further details).

\section{Acknowledgments}

We thank Miur and University of Salerno for financial supports.

Keywords: Organocatalysis . DFT calculations Isoindolinone N,S-acetal · Dynamic kinetic resolution · Homochiral catalysts

[1] For recent reviews on asymmetric synthesis of heterocycles and domino reaction via organocatalysis see: a) D.-J. Cheng, Y.-D. Shao, Adv. Synth. Catal. 2018, 360, 3614-3642; b) T. Chanda, J. C.-G. Zhao, Adv. Synth. Catal. 2018, 360, 2-79; c) D. L. Hughes, Org. Process Res. Dev. 2018, 22, $574-$ 584; d) T. Martzel, J.-F. Lohier, A.-C. Gaumont, J.-F. Briere, S. Perrio, Adv. Synth. Catal. 2018, 360, 2696-2706; e) L. Tian, Y.-C. Luo, X.-Q. Hu, P.-F. Xu, Asian J. Org. Chem. 2016, 5, 580-607; f) L.-Q. Lu, J.-R. Chen, W.-J. Xiao, Acc. Chem. Res. 2012, 45, 1278-93; g) T. Marcelli, Organocatalysis: Cinchona catalysts. Wiley Interdisciplinary Reviews-Computational Molecular Science 2011, 1, pp. 142-152.

[2] For recent reviews, see: a) Y. Zhang, Y. Zhang, O. Ramström, Catal. Rev. -Sci. Eng. 2019, https://doi.org/doi.org/10.1080/01614940.2019.1664031; b) H. Pellesier, Tetrahedron 2016, 72, 3133-3150; c) H. Pellesier, Adv. Synth. Catal. 2011, 353, 659-676; d) W. K. Lee, Y. S. Park, P. Beak, Acc. Chem. Res. 2009, 42, 224-234; e) C. C. Gruber, I. Lavandera, K. Faber, W. Kroutil, Adv. Synth. Catal. 2006, 348, 1789-1805.

[3] For selected examples, see: a) R. Claveau, B. Twamley, S. J. Connon, Chem. Commun. 2018, 54, 3231-3234; b) N. Yoneda, Y. Fujii, A. Matsumoto, K. Asano, S. Matsubara, Nat. Commun. 2017, 8, 1-7; c) J. Blom, T. K. Johansen, F. Jensen, K. A. Jørgensen, Chem. Commun. 2016, 52, 7153-7156; d) S. Wang, S. Zhou, J. Wang, Y. Nian, A. Kawashima, H. Moriwaki, J. L. Aceňa, V. A. Soloshonok, H. Liu, J. Org. Chem. 2015, 80, 9817-9830; e) H. Jiang, K. S. Halskov, T. K. Johansen, K. A. Jørgensen, Chem. Eur. J. 2011, 17, 3842-3846; f) X. Yang, V. B. Birman, Angew. Chem. Int. Ed. 2011, 50, 55535555; Angew. Chem. 2011, 123, 5667; g) A. Lee, A. Michrowska, S. SulzerMosse, B. List, Angew. Chem. Int. Ed. 2011, 50, 1707-1710; Angew. Chem. 2011, 123, 1745; h) S. Hoffmann, M. Nicoletti, B. List, J. Am. Chem. Soc. 2006, 128, 13074-13075; i) J. Clayden, L. W. Lai, Angew. Chem. Int. Ed. 1999, 38, 2556-2558; Angew. Chem. 1999, 111, 2755.

[4] For selected articles and reviews see: a) Q.-C. Zhang, X. Li, X. Wang, S.-J. Li, L.-B. Qu, Y. Lan, D. Wei, Org. Chem. Front. 2019, 6, 679-687; b) T. Földes, Á. Madarász, Á. Révész, Z. Dobi, Sz. Varga, A. Hamza, P. R. Nagy, P. M. Pihko, I. Pápai, J. Am. Chem. Soc. 2017, 139, 17052-17063; c) G. Tanriver, B. Dedeoglu, S. Catak, V. M. Aviyente, R. Š. Žabka, Acc. Chem. Res. 2016, 49, 1250-1262; d) M. Žabka, R. Šebesta, Molecules 2015, 20, 15500-15524; e) I. Papai, in Science of Synthesis. Asymmetric Organocatalysis 2 (Eds.: B. List, K. Maruoka), Thieme Stuttgart: New York, 2012, pp. 601-632; f) P. H.-Y. Cheong, C. Y. Legault, J. M. Um, N. Çelebi-Ölçüm, K. N. 
Houk, Chem. Rev. 2011, 111, 5042-5137; g) A. Hamza, G. Schubert, T. Soos, I. Papai, J. Am. Chem. Soc. 2006, 128, 13151-13160; h) C. Allemann, R. Gordillo, F. R. Clemente, P. H.-Y. Cheong, K. N. Houk, Acc. Chem. Res. 2004, 37, 558-569.

[5] V. Capaccio, A. Capobianco, A. Stanzione, G. Pierri, C. Tedesco, A. Di Mola, A. Massa, L. Palombi, Adv. Synth. Catal. 2017, 359, 2874-2880.

[6] a) J. Suc, I. Dokli, M. Gredicak, Chem. Commun. 2016, 52, 2071-2074; b) S. Nakamura, S. Takahashi, D. Nakane, H. Masuda, Org. Lett. 2015, 17 , 106-109; c) H. Qian, J. Sun, Asian J. Org. Chem. 2014, 3, 387-390; d) X. Fang, Q.-H. Li, H.-Y. Tao, C.-J. Wang, Adv. Synth. Catal. 2013, 355, 327-331; e) H.-Y. Wang, J.-X. Zhang, D.-D. Cao, G. Zhao, ACS Catal. 2013, 3, 22182221 ; f) G. K. Ingle, M. G. Mormino, L. Wojtas, J. C. Antilla, Org. Lett. 2011, 13, 4822-4825.

[7] For selected recent reviews on isoindolinones see a) D. Glavač, M. Gredičak, Synlett 2017, 28, 889-897; b) Z. Lan, Drug Des. Dev. Ther. 2015, 9 , 3377-3391; c) A. Suyavaran, C. Ramamurthy, R. Mareeswaran, Y. V. Shanthi, J. Selvakumar, S. Mangalaraj, M. S. Kumar, C. R. Ramanathan, C. Thirunavukkarasu, Bioorg. Med. Chem. 2015, 23, 488-498; d) A. Di Mola, L. Palombi, A. Massa, Targets Heterocycl. Systems 2014, 18, 113-140; e) A. Di Mola, L. Palombi, A. Massa, Curr. Org. Chem. 2012, 16, 2302-2320.

[8] a) L. A. Bryant, R. Fanelli, A. J. A. Cobb, Beilstein J. Org. Chem. 2016, 12, 429-443; b) T. Marcelli, J. H. van Maarseveen, H. Hiemstra, Angew. Chem. Int. Ed. 2006, 45, 7496-7504; Angew. Chem. 2006, 118, 7658.

[9] X-ray structure of heterochiral crystals of a representative derivative $\mathbf{1}$ is reported in ref. ${ }^{[5]}$

[10] a) A. Di Mola, F. Scorzelli, G. Monaco, L. Palombi, A. Massa, RSC Adv. 2016, 6, 60780-60786; b) M. Perillo, A. Di Mola, R. Filosa, L. Palombi, A. Massa, RSC Adv. 2014, 4, 4239-4246.

[11] For the multi-functionalized catalyst I different conformations are possible and known as anti/trans-open and anti/trans-closed. Even though some of the mentioned conformations lie at similar energies for the isolated catalyst, the conformation anti-open should be favored when the system interacts with the substrate thanks to the largest number of hydrogen bonds that can be established. See, for ex a) G. K. Surya Prakash, F. Wang, M. Rahm, Z. Zhang, C. Ni, J. Shen, G. A. Olah, J. Am. Chem. Soc. 2014, 136, 10418-10431; b) A. Capobianco, A. Di Mola, V. Intintoli, A. Massa, V. Capaccio, L. Roiser, M. Waser, L. Palombi, RSC Adv. 2016, 6 , 31861-31870; c) G. K. Surya Prakash, F. Wang, C. Ni, J. Shen, R. Haiges, A. K. Yudin, T. Mathew, G. A. Olah, J. Am. Chem. Soc. 2011, 133, 99929995; d) A. Urakawa, D. M. Meier, H. Rüegger, A. Baiker, J. Phys. Chem. A 2008, 112, 7250-7255; e) H. Caner, P. U. Biedermann, I. Agranat, Chirality 2003, 15, 637-645.

[12] ${ }^{1} \mathrm{H}-\mathrm{NMR}$ experiments confirm that a dynamic equilibrium with the starting imine is only observed in the presence of the catalyst, being the formation of the intermediate $\mathbf{A}$ quantitative in catalyst-free conditions.

[13] For a review on the classification of DYKAT see: J. Steinreiber, K. Faber, H. Griengl, Chem. Eur. J. 2008, 14, 8060-8072.

[14] a) W. He, Q. Wang, Q. Wang, B. Zhang, X. Sun, S. Zhang, Synlett 2009, 8, 1311-1314; b) H. Qing, Y. Wang, Z. Zheng, S. Chen, Q. Meng, Tetrahedron: Asymmetry 2016, 27, 834-842.

[15] C. Adamo, V. Barone, J. Chem. Phys. 1999, 110, 6158-6170.

[16] a) S. Grimme, P. R. Schreiner, Angew. Chem. Int. Ed. 2018, 57, 4170-4176; Angew. Chem. 2018, 130, 4241; b) S. Grimme, J. Comput. Chem. 2004, 25, 1463-1473.

[17] M. J. Frisch, et al. Gaussian 16 Revision B.01, Gaussian Inc., Wallingford CT, 2016.

[18] A. Schäfer, H. Horn, R. Ahlrichs, J. Chem. Phys. 1992, 97, 2571-2577.

[19] F. Weigend, F. Furche, R. Ahlrichs, J. Chem. Phys. 2003, 119, 12753-12762.

[20] Y. Zhao, D. G. Truhlar, Theor. Chem. Acc. 2008, 120, 215-241.

[21] S. Schenker, C. Schneider, S. B. Tsogoeva, T. Clark, J. Chem. Theory Comput. 2011, 7, 3586.

[22] J. Tomasi, M. Persico, Chem. Rev. 1994, 94, 2027-2094.

[23] V. Barone, M. Cossi, J. Phys. Chem. A 1998, 102, 1995-2001.

Received: October 12, 2019 